\title{
Relation between Early Over- and Undertreatment and Behavioural Problems in Preadolescent Children with Congenital Hypothyroidism
}

\author{
Jacoba J. Bongers-Schokking ${ }^{\text {a }}$ Wilma C.M. Resing ${ }^{b}$ Wilma Oostdijk ${ }^{c}$ \\ Yolanda B. de Rijke ${ }^{d}$ Sabine M.P.F. de Muinck Keizer-Schrama ${ }^{a}$ \\ a Department of Pediatrics, Erasmus MC - Sophia Children's Hospital , University Medical Center Rotterdam, Rotterdam, \\ The Netherlands; ${ }^{b}$ Department of Developmental and Educational Psychology, Faculty of Social Sciences, University of \\ Leiden, Leiden, The Netherlands; ' ${ }^{\mathrm{D}}$ Department of Pediatrics, Leiden University Medical Center, Leiden, The Netherlands; \\ ${ }^{\mathrm{d}}$ Department of Clinical Chemistry, Erasmus MC, University Medical Center Rotterdam, Rotterdam, The Netherlands
}

\author{
Keywords \\ Congenital hypothyroidism · Early overtreatment · \\ Early undertreatment $\cdot \mathrm{ADHD} \cdot$ Autism $\cdot \mathrm{fT}_{4}$ steady state \\ concentrations
}

\begin{abstract}
Objective: Congenital hypothyroidism $(\mathrm{CH})$ per se, when not treated or undertreated, may lead to severe behavioural problems (cretinism), whereas overtreatment of $\mathrm{CH}$ seems associated with attention problems. Design and Methods: For $55 \mathrm{CH}$ patients, prospectively followed from birth until 11 years, parents rated the Child Behaviour Checklist and teachers the Teacher's Report Form at children's ages 6 and 11 years. We related scores regarding Attention, Delinquency, and Aggression (ADA scores, indicative for attention deficit hyperactivity syndrome, ADHD), and scores regarding Withdrawn, Anxious, Social, and Thought problems (WAST scores, indicative for autism) to the occurrence of over- and undertreatment in five age periods. Over- and undertreatment were defined as free thyroxine $\left(\mathrm{fT}_{4}\right)$ concentrations above/below the range of the patient's individual $\mathrm{fT}_{4}$ steady state concentration. Results: ADA scores at 6 and 11 years for patients overtreated in the period 1-3 months postnatally were higher than those for patients who were not overtreat-
\end{abstract}

ed. Patients with severe $\mathrm{CH}$ undertreated in the period 3-6 months postnatally had higher WAST scores at 6 and 11 years than all other patients. Conclusions: This is the first study suggesting that permanent ADHD as well as autism in $\mathrm{CH}$ patients at ages 6 and 11 years are the result of early overtreatment and undertreatment, respectively.

(c) 2018 The Author(s)

Published by S. Karger AG, Basel

\section{Introduction}

Thyroid abnormalities have been associated with attention deficit hyperactivity disorder (ADHD) in various studies [1-3]. This association is most clearly seen in a study on thyroid hormone resistance [1], where the majority of the patients were found to have ADHD. In adolescents with congenital hypothyroidism $(\mathrm{CH})$ the proportion of patients with ADHD was estimated at 30-40\% [2]. In a group of fifty 10 -year-old $\mathrm{CH}$ patients poor attention was seen after overtreatment in the first 6 months

In the final stage of writing this paper, Coot Bongers-Schokking, the first author of this article, unexpectedly passed away. She was founder of the design and hypothesis of this study, and largely contributed to the establishment of the manuscript, and discussions thereof.

\begin{tabular}{ll}
\hline KARGER & $\begin{array}{l}\text { (c) } 2018 \text { The Author(s) } \\
\text { Published by S. Karger AG, Basel }\end{array}$ \\
E-Mail karger@karger.com & This article is licensed under the Creative Commons Attribution- \\
www.karger.com/hrp & $\begin{array}{l}\text { NonCommercial-NoDerivatives 4.0 International License (CC BY- } \\
\text { NC-ND) (http://www.karger.com/Services/OpenAccessLicense). } \\
\text { Usage and distribution for commercial purposes as well as any dis- } \\
\text { tribution of modified material requires written permission. }\end{array}$
\end{tabular}

Sabine M.P.F. de Muinck Keizer-Schrama

Department of Pediatrics, Erasmus MC - Sophia Children's Hospital

University Medical Center Rotterdam, Sp 3435, PO Box 2060

NL-3000 CB Rotterdam (The Netherlands)

E-Mail s.demuinckkeizer-schrama@erasmusmc.nl 
after birth [3]. Two other studies, however, failed to confirm poor impulse control and externalizing problems in $\mathrm{CH}$ patients. These patients were predominantly introvert $[4,5]$. In an earlier study we demonstrated that severe maternal hypothyroxinaemia, in a period when the foetus is still largely dependent on maternal thyroxine $\left(\mathrm{T}_{4}\right)$ supply, led to a 4 -fold higher risk of autism in the off-spring than higher maternal $\mathrm{T}_{4}$ concentrations [6]. The exact mechanism underlying the presence of behavioural problems in $\mathrm{CH}$ is still unclear.

Rovet et al. [7] investigated temperamental behaviour in early-treated $\mathrm{CH}$ patients [7] and found that serum $\mathrm{T}_{4}$ concentrations of patients classified as "difficult" at the age of 6 months had been higher in the period 1-3 months postnatally than those of patients classified as "easy" [7]. This difference in temperament persisted until at least the age of 2 years.

In the study presented here we evaluated behaviour in $\mathrm{CH}$ children by means of questionnaires completed by parents and teachers at different children's ages. The results were related to overtreatment (OT) and undertreatment (UT). Assessment of OT and UT was based upon the individual free $\mathrm{T}_{4}\left(\mathrm{fT}_{4}\right)$ steady state concentrations (SSCs) [8]. We investigated whether behavioural problems in $\mathrm{CH}$ are associated with OT and UT, respectively, and if so, from which period these problems originated, how long they persisted, and whether they equally affected patients with severe and mild $\mathrm{CH}$.

\section{Methods}

\section{Subjects}

The study group was part of a cohort of 61 children (22 male) with early-treated permanent $\mathrm{CH}$ described previously [8-12]. They were born in the Netherlands between February 1993 and July 1996. It was a nationwide study. All patients were under the care of their own local paediatrician. Inclusion and exclusion criteria were described earlier [9]. Included were patients with the diagnosis of permanent $\mathrm{CH}$, on $\mathrm{L}^{-} \mathrm{T}_{4}$ therapy. Exclusion criteria were as follows: risk for abnormal psychomotor development for reasons other than $\mathrm{CH}$ (asphyxia, meningitis, chromosomal abnormalities, a syndrome with severe hypotonia, severe prematurity), having a mother with known thyroid abnormalities, and social reasons (e.g., children of refugees). Severity of $\mathrm{CH}$ was classified according to aetiology [13]. Severe $\mathrm{CH}$ was defined as total incapability to produce $\mathrm{T}_{4}$, and mild $\mathrm{CH}$ as partial incapability $[7,8]$.

\section{Psychological Tests}

At children's ages 6 and 11 years, parents rated the Child Behaviour Checklist (CBCL) [14] and teachers the Teacher's Report Form (TRF) [15]. CBCL and TRF are screening tests, both consisting of 113 questions, to be rated on a 3-point scale, and subdivided in 8 domains of behaviour: Socially withdrawn, Somatic complaints, Anxious/depressed, Social problems, Thought problems, Attention problems, Delinquency, and Aggression. The raw scores can be converted to age-standardized scores, T scores, that can be compared with scores obtained from normative samples of children within the same age range. A higher score means a greater number or intensity of behavioural problems. T scores below 65 are interpreted as normal, between $65-70$ as borderline, and above 70 as clinical. Thyroid status around the test moments was checked. The aggregated score for the domains Attention problems, Delinquency, and Aggression, addressed as ADA score, was determined by taking the mean $\mathrm{T}$ score of these three domains. The aggregated score for the domains Socially withdrawn, Anxious/depressed, Social problems, and Thought problems, addressed as WAST score, was determined by taking the mean $\mathrm{T}$ score of these four domains. The control group at 6 years contained 36 children, and at 11 years 28 children. It comprised healthy, age-matched children, from regular primary schools in the Leiden-Rotterdam region.

\section{Over- and Undertreatment}

Over- and undertreatment status was based on the individual $\mathrm{fT}_{4}$ steady state concentration ( $\mathrm{fT}_{4} \mathrm{SSC}$ ) [7], defined as that $\mathrm{fT}_{4}$ concentration at which it is constant, despite ongoing processes that might change it, such as medication, $\mathrm{T}_{4}$ clearance, and alterations in the equilibrium between the different deiodinase pathways [16]. The rationale of the SSC is that it is not possible to treat $\mathrm{CH}$ patients properly without knowing what euthyroidism means for the individual patient [11]. SSC provides $\mathrm{fT}_{4}$ concentrations to aim at, as well as individual ranges that indicate over- and undertreatment. In healthy, euthyroid subjects and subjects with stable thyroid disease individual SSCs represent the mean value of a series of determinations under stable and euthyroid conditions as much as possible [17-19]. For the determination of SSCs in $\mathrm{CH}$ patients, we assumed that most euthyroid samples would be present in samples with a thyroid stimulating hormone (TSH) between 0.5 and $10 \mathrm{mU} / \mathrm{L}$ and obtained at an age at which $\mathrm{fT}_{4}$ and $\mathrm{TSH}$ have stabilized after the onset of therapy, i.e., from 1.5 months up to 132 months after the start of therapy. Next, samples with $\mathrm{fT}_{4}$ concentrations outside the $95 \%$ CI were excluded (Table 1). This selection procedure yielded a mean of 21 samples per patient, out of the mean of 44 samples that were available per patient. As described

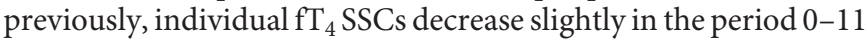
years and are largely independent of the $\mathrm{L}_{-} \mathrm{T}_{4}$ dosage [7]. In the initial period, i.e., from therapy start to 1.5 months later, values are somewhat higher than in the post-initial period without reaching significance: mean (SD) 22.5 (3.0) versus 21.7 (2.6) pmol/L, respectively $(p=0.07)$ (Table 1$)$ [7]. Over- and undertreatment were defined as $\mathrm{fT}_{4}$ concentrations above $+2 \mathrm{SD} /$ below $-2 \mathrm{SD}$ of the individual $\mathrm{fT}_{4}$ SSC. Patients were considered as over-/undertreated (OT/UT) during a specific time period if in that period they had experienced one or more episodes of over- or undertreatment. The interval between 1 month after birth and 11 years of age was subdivided into five periods: $1-3$ months, $3-6$ months, $6-24$ months, 2-6 years, and 6-11 years. Patients were classified per period as OT positive $(\mathrm{OT}+)$ or OT negative (OT-), and as UT positive (UT+) or UT negative (UT-).

\section{Statistical Analysis}

Statistical analysis was done with SPSS version 24.0 (SPSS Inc. Chicago, IL, USA). Eight separate multiple regression procedures 
Table 1. $\mathrm{fT}_{4}$ and TSH SSC values of the $61 \mathrm{CH}$ patients of the original study group [7]

\begin{tabular}{lcccc}
\hline & $\begin{array}{l}\text { Age interval, } \\
\text { months }\end{array}$ & $\begin{array}{l}\text { Samples } \\
\text { per patient, } n\end{array}$ & SSC & CV, \% \\
\hline Post-initial fT 4 SSC, pmol/L & $1.5-132$ & 21.0 & $21.7(2.6)[16.6 ; 28.7]$ & $12.0(3.9)$ \\
Initial fT $_{4}$ SSC, pmol/L & $0.23-1.5$ & 4.6 & $22.5(3.0)[16.2 ; 27.3]$ & $13.2(6.3)$ \\
Post-initial TSH SSC, mU/L & $1.5-132$ & 21.0 & $3.3(1.9)[0.9 ; 5.7]$ & $59.9(13.6)$ \\
\hline
\end{tabular}

SSC values are presented as mean (SD) [95\% CI]. Age interval: age after onset of therapy. CV: mean coefficient of variation $(\mathrm{CV})$ within the individual SSCs. Difference between initial SSCs and SSCs for interval 1.5-132 months: $p=0.07$.

were used to compare the effect of OT/UT on the parental and teachers' ADA and WAST scores at children's ages 6 and 11 years. In this analysis the OT+/OT- and $\mathrm{UT}+/ \mathrm{UT}$ - treatment groups of the five age periods were the independent variables, and ADA and WAST scores at 6 and 11 years the dependent variables. Multiple regressions were applied to identify behavioural score differences between patients with severe and mild $\mathrm{CH}$ within the $\mathrm{OT}+$, OT-, $\mathrm{UT}+$, and UT- groups. ANOVAs were applied to compare $\mathrm{fT}_{4}$ concentrations (in pmol/L and SSC SDS) as well as TSH values of the $\mathrm{OT}+/ \mathrm{OT}-$ and $\mathrm{UT}+/ \mathrm{UT}$ - groups during the five age periods. CBCL and TRF scores of patients and controls were compared with Student $t$ tests. Pearson correlations were performed to find potential associations between the scores at 6 and 11 years. For all tests a significance level of 0.05 was used.

\section{Results}

\section{Subjects and Tests}

The initial cohort consisted of 61 patients (22 male), that at 6 years of 46 patients ( 13 male), and that at 11 years of 55 patients ( 19 male). Of these 55 patients 8 were nonethnic Dutch, i.e., Moroccan or Turkish. According to aetiology, 23 cases of $\mathrm{CH}$ were classified as severe and 32 as mild, with mean (SD) pre-treatment $\mathrm{fT}_{4}$ concentrations of 2.6 (1.0) and 8.7 (3.8) pmol/L, respectively. In the severe group 19 patients had agenesis, and 4 had total dyshormonogenesis; in the mild group 28 patients had an ectopic gland, and 4 patients had partial dyshormonogenesis. Age at onset of treatment was 14.2 (4.6) days, and the initial L-T 4 dose was $8.7(2.2) \mu \mathrm{g} / \mathrm{kg}$. Mean socio-economic status (SES) was $2.13(0.75)$, on a 3-point scale. Follow-up data on $\mathrm{fT}_{4}, \mathrm{TSH}$, and $\mathrm{L}_{-} \mathrm{T}_{4}$ dose were collected.

At 6 years 40 CBCL forms and 31 TRF forms were filled out; at 11 years 55 of both forms were filled. Three patients were formally diagnosed as having ADHD, 2 met the criteria for autism. Two ADHD patients were treated with methylphenidate after the age of 6 years (no medication was taken during testing). For one of those, TRF
ADA scores from 6 to 11 years decreased from 74 to 63 ; for the other scores were comparable (69 and 71).

All but 6 patients had a normal thyroid status at testing. At both test moments 1 patient was undertreated and 2 were overtreated. Parents' and teachers' WAST scores of the 2 hypothyroid patients were below 60; teacher's ADA score for one of them was in the borderline range (69) at age 6 years and in the clinical range (71) at age 11 years. The 2 hyperthyroid patients had teachers' ADA scores of 58 and 64 at 6 years. At 11 years the latter score was 57 . At age 11 years the 2 hyperthyroid patients had teachers' ADA scores of 51 and 69. The latter borderline score could not be compared with a previous score, because it was lacking.

Parental ADA and WAST scores at 6 and 11 years showed a good relationship ( 0.686 and 0.617 , respectively, $p<0.001$ for both). The same holds for the teachers' scores ( 0.818 and 0.575 , respectively, $p<0.001$ ), considering that the rating was done by two different teachers.

\section{Relation of ADA and WAST Scores with Treatment}

Table 2 shows the differences in behavioural scores (ADA and WAST) between the groups with and without overtreatment (OT+/OT-) and with and without undertreatment (UT+/UT-), respectively, for the periods $1-3$, 3-6, and 6-24 months after birth.

Apart from the parental ADA score at age 6 years, ADA scores were positively related to overtreatment in the period 1-3 months after birth (Table 2). Negative associations were established between overtreatment in the period 3-6 months and the ADA scores of both parents and teachers at age 11 years. No significant relation between ADA scores and undertreatment could be found in any of the periods. WAST scores at ages 6 and 11 years were positively related to undertreatment in the period 3-6 months (Table 2), with the exception of the teachers' WAST score at age 6 , possibly due to the small number of 


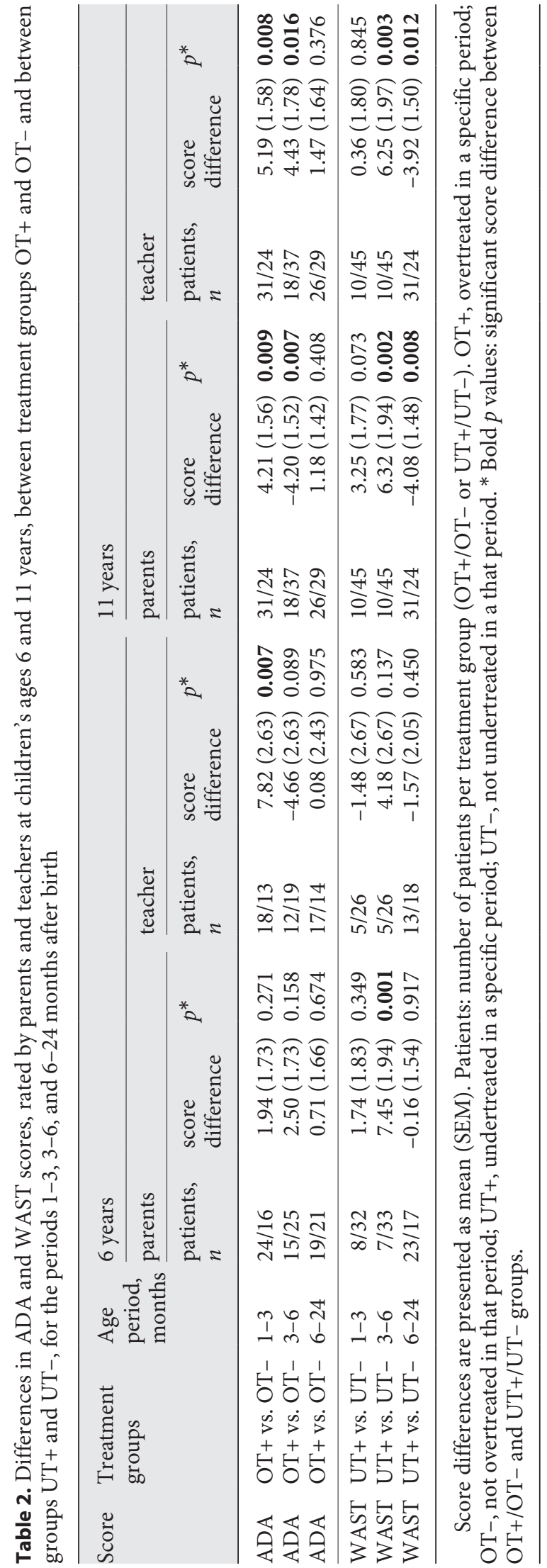

undertreated patients in the UT+ group $(n=5)$. Undertreatment in the period 6-24 months was significantly negatively associated with WAST scores of parents and teachers at age 11 years (Table 2). No significant relation between overtreatment and WAST scores was found in any of the investigated periods. No significant associations were established for the two later periods, from 24 months to 11 years, either between ADA scores and overtreatment or between WAST scores and undertreatment. In all analyses ADA scores of the OT- groups and WAST scores of the UT-groups were non-significantly different from those of the control groups ( $p \geq 0.084$ for all).

Figure 1 shows the combined mean behavioural scores of the ratings at 6 and 11 years by parents and teachers, for the period 1-3 months (ADA scores; Fig. 1a) and 3-6 months (WAST sores; Fig. 1b). Mean ( \pm SEM) combined ADA scores of the OT+ and OT- groups differed significantly: $55.9(0.7)$ (number of ratings, $n=104$ ) vs. 52.8 (78) ( $n=78 ; p<0.001)$, as did the mean combined WAST scores of the UT+ and UT- groups: $58.1(1.3)(n=32)$ vs. $53.0(0.3)(n=149 ; p<0.001)$.

\section{Relation of ADA and WAST Scores with Type of $\mathrm{CH}$}

Table 3 shows the differences in mean ADA and WAST scores, rated by parents and teachers at children's ages 6 and 11 years, between severe and mild $\mathrm{CH}$ patients in the treatment groups $\mathrm{OT}+, \mathrm{OT}-, \mathrm{UT}+$, and UT-, for the periods 1-3 months (ADA scores) and 3-6 months (WAST scores). There were 13 and 16 severe and mild cases, respectively, in the OT+ group, 10 and 16 cases in the OTgroup, 5 and 5 cases in the UT+ group, and 18 and 27 cases in the UT- group. The ADA scores did not differ significantly between severe and mild patients in the OT+ or OT- groups (Fig. 1a). Highly significant differences were found, however, between the severe and mild patients in all UT+ groups $(p<0.001$ for all) (Table 3; Fig. 1b). The risk of a WAST score $>60$ was 33.3 (95\% CI $10.3 ; 108.0$ )-fold higher for a patient with severe $\mathrm{CH}$ and undertreated in the period 3-6 months than for all other $\mathrm{CH}$ patients. Pre-treatment $\mathrm{fT}_{4}$ concentrations of patients with $\mathrm{UT}+$ and severe $\mathrm{CH}$ were lower than those of patients with UT- and severe CH: -9.0 (1.3) vs. -7.2 (2.4) SSC SDS, respectively ( $p=0.043)$. In the UT+ group, mean $\mathrm{fT}_{4}$ (in SSC SDS) and TSH concentrations of the severe and mild patients in the period 3-6 months were comparable: $\mathrm{fT}_{4}-1.17$ (1.47) vs. -1.19 (1.01) SSC SDS, respectively ( $p=0.986$ ); TSH 16.1 (8.5) vs. 14.5 (9.3) $\mathrm{mU} / \mathrm{L}$, respectively $(p=0.773)$. The same holds for the mean duration of undertreatment: $1.61(0.77)$ vs. 1.81 (0.43) months, respectively ( $p=0.673)$. 
Table 3. Differences in ADA and WAST scores, rated by parents and teachers at 6 and 11 years, between severe and mild CH patients of treatment groups OT+, OT-, UT+, and UT-, for the period 1-3 months (ADA scores) and 3-6 months (WAST scores)

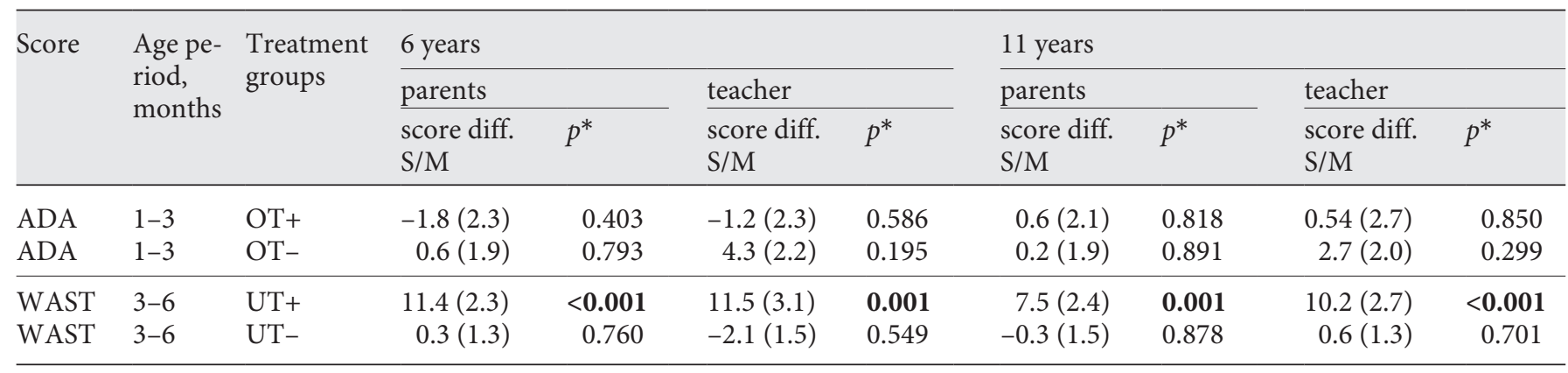

Score differences are presented as mean (SEM). Score diff. S/M: score difference between severe and mild $\mathrm{CH}$ within the indicated group. * Bold $p$ values indicate significant results.

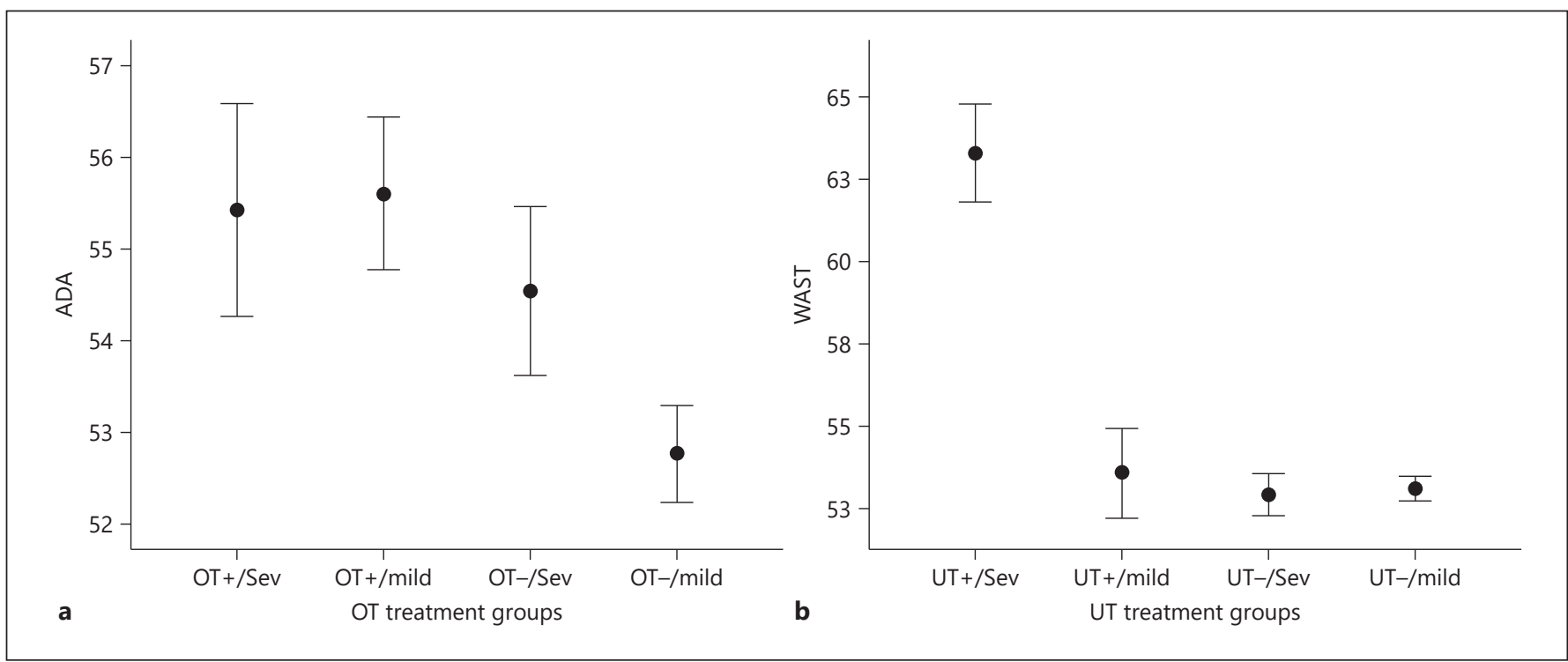

Fig. 1. a Mean combined ADA scores ( \pm SEM), rated at children's ages 6 and 11 years by parents and teachers, of over- and not overtreated patients in the period 1-3 months, subdivided into treatment groups OT+/severe, OT+/mild, OT-/severe, and OT-/mild. Difference between ADA scores of OT+ and OT- patients: $p<$ 0.001; difference between severe and mild congenital hypothyroidism $(\mathrm{CH})$ patients in the $\mathrm{OT}+$ group: not significant. b Mean

\section{$\mathrm{fT}_{4}$ and TSH Concentrations}

In the period 1-3 months postnatally $\mathrm{fT}_{4}$ concentrations (in $\mathrm{pmol} / \mathrm{L}$ and in individual SSC SDS values) in the $\mathrm{OT}+$ group were higher and TSH values were lower than those in the OT- group ( $p<0.001$ for all) (Table 4; Fig. 2a). Likewise, in the period 3-6 months $\mathrm{fT}_{4}$ concentrations in the UT+ group were lower and TSH values were higher

$\mathrm{CH}$ Treatment and Preadolescent Behaviour
WAST scores ( \pm SEM), rated at ages 6 and 11 by parents and teachers, of under- and not undertreated patients in the period 3-6 months, subdivided into treatment groups UT+/severe, UT+/ mild, UT-/severe, and UT-/mild. Difference between WAST scores of UT+ and UT- patients: $p<0.001$; difference between severe and mild $\mathrm{CH}$ patients in the UT+ group: $p<0.001$. OT, overtreatment; UT, undertreatment; Sev, severe. than those in the UT- group ( $p<0.001$ for all) (Table 4; Fig. 2b).

\section{Relation of ADA and WAST Scores with Other Variables}

Regarding the period 1-3 months, patients in the OT+ and OT- groups did not differ in initial $\mathrm{L}_{-} \mathrm{T}_{4}$ dose: 9.2 
Table 4. $\mathrm{fT}_{4}$ and $\mathrm{TSH}$ concentrations of the OT+/OT- and UT+/UT- groups in age periods 1-3, 3-6, and 6-24 months

\begin{tabular}{|c|c|c|c|c|c|c|c|c|c|}
\hline $\begin{array}{l}\text { Age period, } \\
\text { months }\end{array}$ & $\begin{array}{l}\text { Treatment } \\
\text { groups }\end{array}$ & $\begin{array}{l}\text { Patients, } \\
n\end{array}$ & $\begin{array}{l}\text { Samples, } \\
n\end{array}$ & $\begin{array}{l}\mathrm{fT}_{4}, \\
\mathrm{pmol} / \mathrm{L}\end{array}$ & $p^{*}$ & $\begin{array}{l}\mathrm{fT}_{4} \\
\text { SSC SDS }\end{array}$ & $p^{*}$ & $\begin{array}{l}\mathrm{TSH}, \\
\mathrm{mU} / \mathrm{L}\end{array}$ & $p^{*}$ \\
\hline $1-3$ & $\begin{array}{l}\text { OT+ } \\
\text { OT- }\end{array}$ & $\begin{array}{l}29 \\
26\end{array}$ & $\begin{array}{l}139 \\
123\end{array}$ & $\begin{array}{l}25.8(0.7) \\
21.3(0.6)\end{array}$ & $<0.001$ & $\begin{array}{r}2.16(0.27) \\
-0.59(0.30)\end{array}$ & $<0.001$ & $\begin{array}{l}7.6(2.2) \\
21.7(3.2)\end{array}$ & $<0.001$ \\
\hline $3-6$ & $\begin{array}{l}\text { OT+ } \\
\text { OT- }\end{array}$ & $\begin{array}{l}18 \\
37\end{array}$ & $\begin{array}{r}59 \\
102\end{array}$ & $\begin{array}{l}27.6(1.2) \\
21.4(0.7)\end{array}$ & $<0.001$ & $\begin{array}{r}2.66(0.43) \\
-0.10(0.21)\end{array}$ & $<0.001$ & $\begin{array}{l}3.1(1.4) \\
9.1(1.5)\end{array}$ & 0.012 \\
\hline $6-24$ & $\begin{array}{l}\text { OT+ } \\
\text { OT- }\end{array}$ & $\begin{array}{l}26 \\
29\end{array}$ & $\begin{array}{l}249 \\
290\end{array}$ & $\begin{array}{l}22.9(0.7) \\
20.1(0.6)\end{array}$ & 0.003 & $\begin{array}{r}0.44(0.18) \\
-0.87(0.22)\end{array}$ & $<0.001$ & $\begin{array}{l}5.4(1.0) \\
9.6(1.2)\end{array}$ & 0.009 \\
\hline $1-3$ & $\begin{array}{l}\text { UT+ } \\
\text { UT- }\end{array}$ & $\begin{array}{l}10 \\
45\end{array}$ & $\begin{array}{r}51 \\
211\end{array}$ & $\begin{array}{l}19.0(1.5) \\
25.1(0.8)\end{array}$ & $<0.001$ & $\begin{array}{r}-1.22(0.73) \\
1.53(0.35)\end{array}$ & $<0.001$ & $\begin{array}{l}24.4(6.5) \\
10.7(2.2)\end{array}$ & $<0.001$ \\
\hline $3-6$ & $\begin{array}{l}\text { UT+ } \\
\text { UT- }\end{array}$ & $\begin{array}{l}10 \\
45\end{array}$ & $\begin{array}{r}35 \\
126\end{array}$ & $\begin{array}{l}19.0(1.3) \\
24.7(0.9)\end{array}$ & $<0.001$ & $\begin{array}{r}-0.77(0.62) \\
1.27(0.37)\end{array}$ & $<0.001$ & $\begin{array}{l}14.1(4.5) \\
5.5(1.3)\end{array}$ & $<0.001$ \\
\hline $6-24$ & $\begin{array}{l}\text { UT+ } \\
\text { UT- }\end{array}$ & $\begin{array}{l}31 \\
24\end{array}$ & $\begin{array}{l}296 \\
243\end{array}$ & $\begin{array}{l}20.1(0.6) \\
22.6(0.7)\end{array}$ & $<0.001$ & $\begin{array}{r}-0.83(0.20) \\
0.53(0.18)\end{array}$ & $<0.001$ & $\begin{array}{l}8.9(1.5) \\
4.6(1.2)\end{array}$ & $<0.001$ \\
\hline
\end{tabular}

$\mathrm{fT}_{4}$ and TSH concentration values are presented as mean (SEM). * Bold p values: significant difference between OT+/OT- and UT+/ $\mathrm{UT}$ - groups.

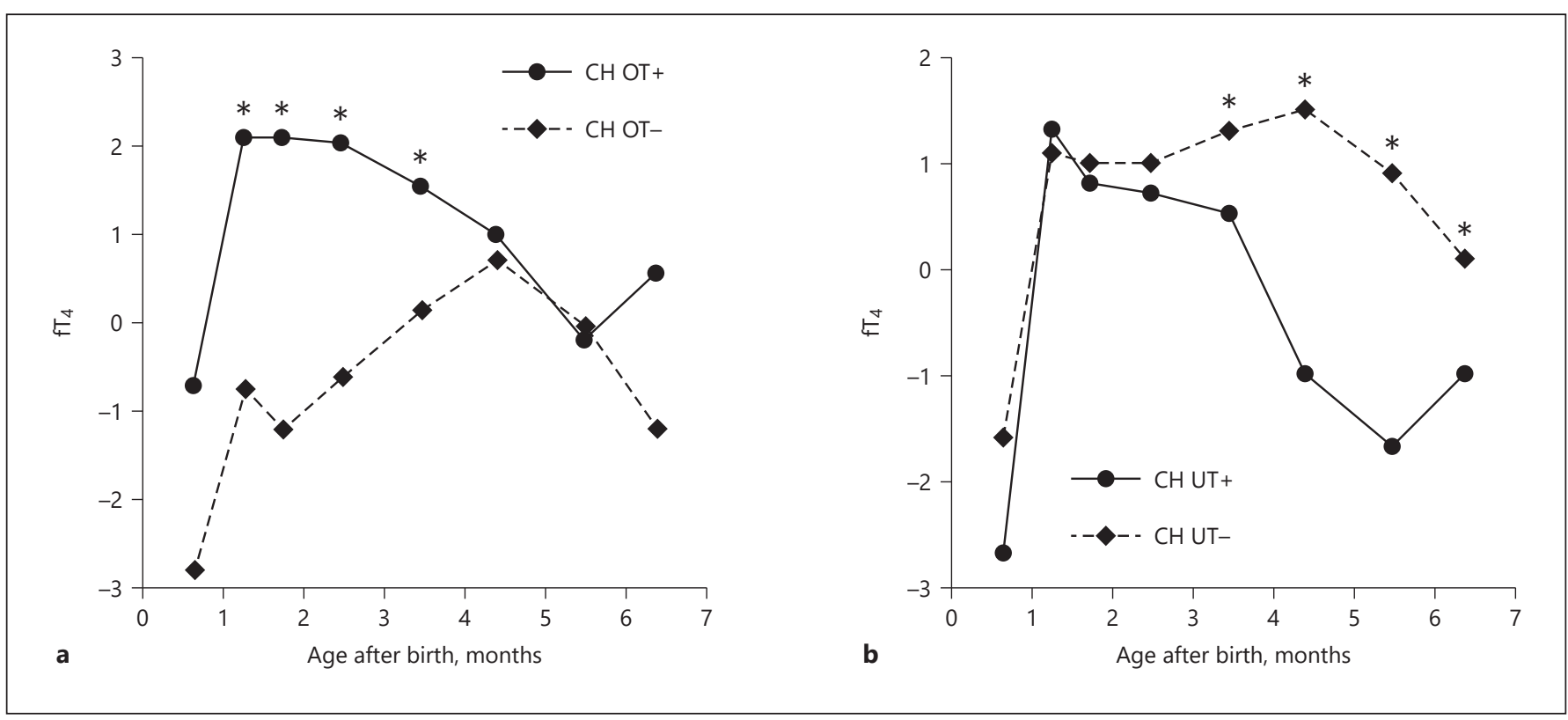

Fig. 2. Mean $\mathrm{fT}_{4}$ concentrations (in SSC SDS) of the study group from initiation of therapy to 7 months. a OT+ and OT- patients of the period 1-3 months after birth. b UT+ and UT- patients of the period 3-6 months after birth. ${ }^{*} p<0.001$ between OT+/OT- values and between UT+/UT- values. $\mathrm{CH}$, congenital hypothyroidism; OT, overtreatment; UT, undertreatment.

(2.0) vs. $8.4(2.0) \mu \mathrm{g} / \mathrm{kg}(p=0.057)$, day of onset of treatment: $16.1(6.2)$ vs. $13.4(3.0)$ days $(p=0.109), \mathrm{L}^{-} \mathrm{T}_{4}$ dose: $6.7(1.7)$ vs. $6.7(1.5) \mu \mathrm{g} / \mathrm{kg}(p=0.858)$, or SES: $2.12(0.73)$ vs. $2.04(0.77)(p=0.409)$. The groups differed significantly, however, in $\mathrm{fT}_{4}$ increase during the first week after therapy onset: $7.2(4.0)$ vs. $4.3(2.7)$ SSC SDS ( $p=0.004)$
(Fig. 2a). A higher $\mathrm{fT}_{4}$ increase during the first week was associated with a higher teachers' ADA score at age 11 $(p=0.015)$. The duration of the overtreatment episodes in the period 1-3 months in the OT+ group: $0.85(0.23)$ months, was not related to the ADA scores. 
Regarding the period 3-6 months, the patients of the $\mathrm{UT}+$ and UT - groups did not differ in initial $\mathrm{L}_{-} \mathrm{T}_{4}$ dose: 8.5 (1.9) vs. $8.6(2.3) \mu \mathrm{g} / \mathrm{kg}(p=0.857)$, day of onset of treatment: $12.4(8.1)$ vs. $14.4(4.8)$ days $(p=0.209)$, SES: $2.30(0.68)$ vs. $2.09(0.76)(p=0.424)$, or $\mathrm{fT}_{4}$ increase during the first week: $12.5(9.0)$ vs. $14.2(9.9) \mathrm{pmol} / \mathrm{L}$ ( $p=$ $0.430)$. The UT+ and UT- groups differed, however, in $\mathrm{L}-\mathrm{T}_{4}$ dose in the period 3-6 months: 4.6 (1.0) vs. 5.6 (1.4) $\mu \mathrm{g} / \mathrm{kg}(p=0.032)$ (Fig. 2b). The duration of the undertreatment episodes in the period 3-6 months in the UT+ group: $1.71(0.59)$ months, was not related to the WAST scores $(p=0.308)$. The pre-treatment $\mathrm{fT}_{4}$ concentrations (in SSC SDS) of the UT+ patients with severe $\mathrm{CH}$ were lower than those of severe cases in the UT-group: -9.0 (1.4) vs. -7.2 (2.4) SSC SDS ( $p=0.043)$.

\section{Discussion}

Our data suggest that $\mathrm{CH}$ patients who experienced one or more overtreatment episodes in the period 1-3 months postnatally may show behavioural problems at a later age, especially poor attention and externalizing behavioural problems. Severe $\mathrm{CH}$ patients who had been undertreated in the period 3-6 months postnatally more frequently showed behavioural problems like introversion, anxiety, social problems, and thought problems than mild $\mathrm{CH}$ patients and patients who were not undertreated. Problems were not present in all over- and undertreated patients, but if present at the age of 6 years seem to be sustained at the age of 11 years. Both over- and undertreated $\mathrm{CH}$ patients in the indicated periods presented with a specific pattern of CBCL and TRF elevations for the domains included in the ADA and WAST scores, resembling the patterns found for ADHD and autism spectrum disorders (ASD), respectively [20-22]. Overtreatment in the period 1-3 months equally affected patients with severe and mild $\mathrm{CH}$ - as was also found in another study [6] - suggesting a postnatal cause for the high ADA scores. Undertreatment in the period 3-6 months predominantly affected patients with severe $\mathrm{CH}$, with a high risk for ASD-like problems, suggesting an additional factor, perhaps from prenatal origin, rendering patients with severe $\mathrm{CH}$ more vulnerable for postnatal hypothyroidism. The pre-treatment $\mathrm{fT}_{4}$ concentrations of the UT+ patients with severe $\mathrm{CH}$ were among the lowest values of all severe cases in our study, suggesting a severe intrauterine $\mathrm{T}_{4}$ deficiency. In an earlier study we found an association between early severe maternal hypothyroxinaemia and an increased risk for autism [21]. Another study

$\mathrm{CH}$ Treatment and Preadolescent Behaviour demonstrated that very low $\mathrm{T}_{4}$ concentrations at birth $(<\mathrm{P} 3)$ were related to a higher risk for ASD [23]. Other factors, like for instance a genetic factor, may of course also be involved in the ADA as well as WAST elevations.

Behavioural problems could only be related to overand undertreatment in the early periods $1-3$ and 3-6 months, respectively, suggesting that normal $\mathrm{fT}_{4}$ concentrations in these short time windows are essential for preventing behavioural problems at a later age. We assume that over- and undertreatment in these respective periods are causative factors for the high ADA and WAST scores, and that the negative associations between behavioural scores and over- and undertreatment in the subsequent periods, i.e., 3-6 and 6-24 months, respectively, are a consequence of the positive associations in the previous periods. A negative association in this respect means that the behavioural scores for the groups without over- and undertreatment were higher than those for the groups with over- and undertreatment. These negative associations were the result of the high behavioural scores for several patients who had been over- or undertreated in the periods $1-3$ or 3-6 months, respectively, but not in the subsequent periods. The absence of over- or undertreatment in these subsequent periods is unlikely to be a causative factor for the high behavioural scores. If the absence of over- and undertreatment would be a causative factor, a substantial proportion of all healthy newborns with normal thyroid function without over- or undertreatment in these periods would show ADHD-like or ASD-like behaviour, which is obviously not the case. Furthermore, the conclusion that overtreatment in the period 1-3 months is a causative factor for high ADA scores, and that the absence of overtreatment in the period 3-6 months is not, is in line with previous studies $[3,6]$. One of these [6] suggests that at least a considerable proportion of the "difficult" patients experienced overtreatment in the period 1-3 months, because at 3 years they showed more advanced motor development than did the "easy" patients. The other study [3] showed that poor attention in $\mathrm{CH}$ patients at the age of 10 years was predicted by the number of overtreatment episodes, defined as TSH $<0.05$ $\mathrm{mU} / \mathrm{L}$, during the first 6 months. Interestingly, as in the present study, the highest mean $\mathrm{fT}_{4}$ concentrations in that study were found in the period 1-3 months after birth.

On the other hand, studies dating from the early years of the $\mathrm{CH}$ screening programmes failed to confirm poor impulse control and externalizing problems in $\mathrm{CH}$ patients $[4,5]$. At 7.5 years these children showed normal impulse control and at 7.5 and 9.5 years were predominantly introvert, similar to our patients undertreated in 
Table 5. $\mathrm{fT}_{4}$ concentrations of the first three follow-up samples, at 4.3, 9.2, and 17.0 days, by initial $\mathrm{L}-\mathrm{T}_{4}$ dose and minimal initial $\mathrm{fT}_{4}$ deficit

\begin{tabular}{llcl}
\hline \multirow{2}{*}{$\begin{array}{l}\text { Initial L-T } \\
\mu \mathrm{g} / \mathrm{kg}\end{array}$} & \multicolumn{4}{l}{ Minimal initial $\mathrm{fT}_{4}$ deficit, $\mathrm{pmol} / \mathrm{L}$} \\
\cline { 2 - 4 } & $<10 \mathrm{pmol} / \mathrm{L}$ & $10-15 \mathrm{pmol} / \mathrm{L}$ & $>15 \mathrm{pmol} / \mathrm{L}$ \\
\hline 5.0 & $-0.7[-2.4 ; 1.1]$ & $-2.3[-3.9 ;-0.7]$ & $-4.0[-5.4 ;-2.5]$ \\
7.5 & $\mathbf{1 . 0}[-\mathbf{0 . 7} \mathbf{2 . 7}]$ & $0.7[-2.1 ; 0.8]$ & $-2.3[-3.7 ;-0.9]$ \\
10.0 & $\mathbf{2 . 7}[\mathbf{1 . 2} \mathbf{4 . 1}]$ & $\mathbf{1 . 0}[-\mathbf{0 . 1} \mathbf{2 . 0}]$ & $0.7[-1.7 ; 0.5]$ \\
12.5 & $\mathbf{4 . 3}[\mathbf{1 . 9} \mathbf{6 . 7}]$ & $\mathbf{2 . 7}[\mathbf{0 . 3} \mathbf{5 . 1}]$ & $\mathbf{1 . 0}[-\mathbf{1 . 0} \mathbf{3 . 0}]$ \\
15.0 & $\mathbf{5 . 9}[\mathbf{3 . 6} \mathbf{8 . 4}]$ & $\mathbf{4 . 3}[\mathbf{1 . 9} \mathbf{6 . 7}]$ & $\mathbf{2 . 7}[\mathbf{0 . 7} \mathbf{4 . 7}]$ \\
\hline
\end{tabular}

$\mathrm{fT}_{4}$ concentrations are presented as mean [95\% CI]. Minimal initial $\mathrm{fT}_{4}$ deficit: difference between -2 SD value of the $95 \%$ CI of the $\mathrm{fT}_{4} \mathrm{SSC}$ range of the whole cohort, i.e., $16.6 \mathrm{pmol} / \mathrm{L}(1.28 \mathrm{ng} / \mathrm{dL})$, and individual pre-treatment $\mathrm{fT}_{4}$. Fields with bold figures: increased risk of overtreatment, i.e., $\mathrm{fT}_{4}$ concentration $>+2$ SDS, relative to the individual SSCs of the patients. Reprinted from Bongers et al. [11] with permission from the authors. the period 3-6 months. The findings could not be related to under- or overtreatment, because follow-up data of $\mathrm{fT}_{4}$ and TSH were not collected. Initiation of therapy was late (27 days) and the starting $\mathrm{L}-\mathrm{T}_{4}$ dosage was low $(6 \mu \mathrm{g} / \mathrm{kg})$. Circumstantial evidence suggests that this regimen will only sporadically lead to overtreatment, but more frequently to undertreatment [24-26]. In the studies in question, also dating from the early years of $\mathrm{CH}$ screening, mean TSH was relatively high $(>10 \mathrm{mU} / \mathrm{L})[23,25]$ and mean $\mathrm{T}_{4}$ relatively low $(130-145 \mathrm{nmol} / \mathrm{L})$ during the first year [24-26]. This suggests that in the studies that found predominantly introvert behaviour $[4,5]$ only few of the patients had been overtreated in the period 1-3 months after birth, explaining the absence of poor impulse control and externalizing problems. Still, a substantial proportion of them may have been undertreated in the period 3-6 months, explaining the introvert behaviour, as also found in our study.

Behavioural problems in $\mathrm{CH}$ may be associated with thyroid status at the time of testing [27], but then are mostly transient. We believe that this phenomenon has had little impact in our study, because only few patients were dysthyroid at testing and their ADA and WAST scores were not consistently associated with over- or undertreatment.

We used the $\mathrm{fT}_{4}$ SSC method to assess under- and overtreatment $[7,11]$ because several overtreated patients could have been missed with the use of TSH age-specific reference ranges. In $\mathrm{CH}$, especially during the first 24 months, high $\mathrm{fT}_{4}$ concentrations fail to suppress $\mathrm{TSH}$ concentrations to the low values found in healthy subjects [11], probably due to a resistance of the hypothalamicpituitary-thyroid axis [28]. Moreover, the TSH response to increasing $\mathrm{fT}_{4}$ values is delayed and quantitatively less than in healthy individuals [11]. Still, overtreated patients may also be missed with the use of $\mathrm{fT}_{4}$ age-specific reference ranges, because the ranges are too wide and two fixed upper and lower limit values will never be able to properly distinguish between normal or abnormal in all $\mathrm{CH}$ patients, whatever values are chosen [11].

A drawback of our study is its relative small sample size. Still, the longitudinal design allowed obtaining CBCL as well as TRF ratings twice, which importantly strengthened the results.

Regarding the optimum treatment regimen, we recommend choosing an initial $\mathrm{L}^{-} \mathrm{T}_{4}$ dosage with which early overtreatment is avoided as much as possible. A limiting factor is that the individual $\mathrm{fT}_{4} \mathrm{SSC}$ value, the main target of treatment, is not known at the beginning of therapy. We have designed an initial dosage scheme (Table 5) [11] that shows which $\mathrm{fT}_{4}$ concentrations might be expected in the first 4-17 days with a specific $\mathrm{L}^{-\mathrm{T}_{4}}$ dosage and considering the patient's minimal initial $\mathrm{fT}_{4}$ deficit. Minimal initial $\mathrm{fT}_{4}$ deficit was defined as the $\mathrm{fT}_{4}$ difference between the lower limit of the $95 \% \mathrm{CI}$ of the $\mathrm{fT}_{4} \mathrm{SSCs}$ of the total $\mathrm{CH}$ cohort, i.e., $16.6 \mathrm{pmol} / \mathrm{L}(1.28 \mathrm{ng} / \mathrm{dL})$, and the individual pre-treatment $\mathrm{fT}_{4}$. Thereafter, $\mathrm{fT}_{4}$ and $\mathrm{TSH}$ should be checked frequently to avoid both over-and undertreatment.

In conclusion, not only should the prevention of cognitive damage be considered a major aim of $\mathrm{CH}$ screening and treatment, but also the prevention of neuropsychological damage. Although clinically relevant behavioural problems were only found in a limited number of our patients, mainly due to the small sample size of our cohort, it seems relevant to screen all $\mathrm{CH}$ patients on behavioural problems. Our study is the first to show that both early over- and undertreatment may lead to permanent 
and distinct behavioural problems: early overtreatment to ADHD and early undertreatment to ASD. The clinical impact of our findings is obvious: adequate treatment may prevent serious behavioural complications. Future studies will have to confirm this.

\section{Acknowledgements}

We are indebted to our patients and their parents for their cooperation in this long study. We also want to thank the participating paediatricians for their willingness to make their patients files available to us.

\section{Statement of Ethics}

The study was approved by the privacy committee of the $\mathrm{CH}$ Screening Board and by the Erasmus MC ethics review board. Written informed consent was obtained from all parents.

\section{Disclosure Statement}

None of the authors have competing financial interests.

\section{Funding Sources}

This study was financially supported by unrestricted grants from the Theia Foundation, Jan Dekker \& Ludgardine Bouwman Foundation, and Zilveren Kruis.

\section{Author Contributions}

Dr. de Muinck Keizer-Schrama and Dr. Bongers-Schokking conceived the study and were responsible for data collection and analysis. Prof. de Rijke was involved in the biochemical aspects of the study. Prof. Resing conducted the psychological testing and evaluation of the patients. Dr. Oostdijk was, as paediatric endocrinologist, involved in the treatment of the children. All members of the team participated in writing the paper.

\section{References}

1 Hauser P, Zametkin AJ, Martinez P, Vitiello B, Matochik JA, Mixson AJ, et al. Attention deficit-hyperactivity disorder in people with generalized resistance to thyroid hormone. $\mathrm{N}$ Engl J Med. 1993 Apr;328(14):997-1001.

2 Rovet JF. Congenital hypothyroidism: longterm outcome. Thyroid. 1999 Jul;9(7):741-8.

3 Álvarez M, Iglesias Fernández C, Rodríguez Sánchez A, Dulín Lñiguez E, Rodríguez Arnao MD. Episodes of overtreatment during the first six months in children with congenital hypothyroidism and their relationships with sustained attention and inhibitory control at school age. Horm Res Paediatr. 2010; 74(2):114-20.

4 Kooistra L, Vulsma T, van der Meere J. An investigation of impulsivity in children with early-treated congenital hypothyroidism. Dev Neuropsychol. 2004;26(2):595-610.

5 Kooistra L, Stemerdink N, van der Meere J, Vulsma T, Kalverboer AF. Behavioural correlates of early-treated congenital hypothyroidism. Acta Paediatr. 2001 Oct;90(10): 1141-6.

6 Román GC, Ghassabian A, Bongers-Schokking JJ, Jaddoe VW, Hofman A, de Rijke YB, et al. Association of gestational maternal hypothyroxinemia and increased autism risk. Ann Neurol. 2013 Nov;74(5):733-42.

7 Rovet JF, Ehrlich RM, Sorbara DL. Effect of thyroid hormone level on temperament in infants with congenital hypothyroidism detected by screening of neonates. J Pediatr. 1989 Jan;114(1):63-8.
8 Bongers-Schokking JJ, de Ridder MA, de Rijke YB, de Muinck Keizer-Schrama SM. Experience in treating congenital hypothyroidism: implications regarding free T4 and TSH steady state concentrations during optimal levothyroxine treatment. Thyroid. 2013 Feb; 23(2): $160-5$

9 Bongers-Schokking JJ, Resing WC, de Rijke YB, de Ridder MA, de Muinck Keizer-Schrama SM. Cognitive development in congenital hypothyroidism: is overtreatment a greater threat than undertreatment? J Clin Endocrinol Metab. 2013 Nov;98(11):4499-506.

10 Bongers-Schokking JJ, Koot HM, Wiersma D, Verkerk PH, de Muinck Keizer SM. Influence of timing and dose of thyroid hormone replacement on development in infants with congenital hypothyroidism. J Pediatr. 2000 Mar;136(3):292-7.

11 Bongers-Schokking JJ, de Muinck KeizerSchrama SM. Influence of timing and dose of thyroid hormone replacement on mental, psychomotor, and behavioral development in children with congenital hypothyroidism. J Pediatr. 2005 Dec;147(6):768-74.

12 Bongers-Schokking JJ, Resing WC, Oostdijk W, de Rijke YB, de Muinck Keizer-Schrama SM. Individualized treatment to optimize eventual cognitive outcome in congenital hypothyroidism. Pediatr Res. 2016 Dec;80(6): 816-23.
13 Léger J, Olivieri A, Donaldson M, Torresani T, Krude H, van Vliet G, polak M, Butler G; ESPE-PES-SLEP-JSPE-APEG-APPES-ISPAE; Congenital Hypothyroidism Conference Group. European Society for Paediatric Endocrinology consensus guidelines on screening, diagnosis, and management of congenital hypothyroidism. J Clin Endocrinol Metab. 2014 Feb;99(2):363-84.

14 Achenbach TM. Manual for the Child Behavior Checklist/4-18, YSR, and TRF profiles. Burlington (VT): University of Vermont, Department of Psychiatry; 1991.

15 Achenbach TM. Manual for the Teacher's Report Form and 1991 TRF profile. Burlington (VT): University of Vermont, Department of Psychiatry; 1991.

16 Friedrichsen S, Christ S, Heuer H, Schäfer MK, Mansouri A, Bauer K, et al. Regulation of iodothyronine deiodinases in the Pax8-/mouse model of congenital hypothyroidism. Endocrinology. 2003 Mar;144(3):777-84.

17 Andersen S, Pedersen KM, Bruun NH, Laurberg P. Narrow individual variations in serum $\mathrm{T}(4)$ and $\mathrm{T}(3)$ in normal subjects: a clue to the understanding of subclinical thyroid disease. Clin Endocrinol Metab. 2002 Mar;87(3): 1068-72.

18 Biersack HJ, Hartmann F, Rödel R, Reinhardt M. Long term changes in serum T4, T3, and TSH in benign thyroid disease: proof of a narrow individual variation. Nuklearmedizin. 2004 Oct;43(5):158-60. 
19 Karmisholt J, Andersen S, Laurberg P. Variation in thyroid function tests in patients with stable untreated subclinical hypothyroidism. Thyroid. 2008 Mar;18(3):303-8.

20 Warnick EM, Bracke MB, Kasl S. Screening efficiency of the Child behavior Checklist and Strengths and Difficulties Questionnaire: A systematic review. Child Adolesc Ment Health. 2008 Sep;13(3):140-7.

21 Rovet JF, Hepworth SL. Dissociating attention deficits in children with ADHD and congenital hypothyroidism using multiple CPTs. J Child Psychol Psychiatry. 2001 Nov;42(8): 1049-56.

22 Mazefski CA, Anderson R, Connor CM, Minshew N. Child Behavior Checklist for schoolaged children with autism: preliminary evi- dence of pattern suggesting the need of referral. J Psychopathol Behav Assess. 2011 Mar; 33(1):31-7.

23 Hoshiko S, Grether JK, Windham GC, Smith D, Fessel K. Are thyroid hormone concentrations at birth associated with subsequent autism diagnosis? Autism Res. 2011 Dec;4(6): 456-63.

24 Hulse JA, Grant DB, Jackson D, Clayton BE. Growth, development, and reassessment of hypothyroid infants diagnosed by screening. Br Med J (Clin Res Ed). 1982 May;284(6327): 1435-7.

25 New England Congenital Hypothyroidism Collaborative. Characteristics of infantile hypothyroidism discovered on neonatal screening. J Pediatr. 1984 Apr;104(4):539-44.
26 Bongers-Schokking JJ, Colon EJ, Mulder PG, Hoogland RA, de Groot CJ, Van den Brande JL. Influence of treatment on the maturation of the somesthetic pathway in infants with primary congenital hypothyroidism during the first year of life. Pediatr Res. 1993 Jul; 34(1):73-8.

27 Rovet JF. Congenital hypothyroidism: an analysis of persisting deficits and associated factors. Child Neuropsychol. 2002 Sep;8(3): 150-62.

28 Fisher DA, Schoen EJ, La Franchi S, Mandel SH, Nelson JC, Carlton EI, et al. The hypothalamic-pituitary-thyroid negative feedback control axis in children with treated congenital hypothyroidism. J Clin Endocrinol Metab. 2000 Aug;85(8):2722-7. 